This item was submitted to Loughborough's Research Repository by the author.

Items in Figshare are protected by copyright, with all rights reserved, unless otherwise indicated.

\title{
A multi-physics multi-scale approach in engine design analysis
}

PLEASE CITE THE PUBLISHED VERSION

PUBLISHER

Professional Engineering Publishing / @ IMECHE

VERSION

VoR (Version of Record)

LICENCE

CC BY-NC-ND 4.0

REPOSITORY RECORD

Perera, M.S. Malika, Stephanos Theodossiades, and Homer Rahnejat. 2019. "A Multi-physics Multi-scale Approach in Engine Design Analysis”. figshare. https://hdl.handle.net/2134/4679. 
This item was submitted to Loughborough's Institutional Repository (https://dspace.lboro.ac.uk/) by the author and is made available under the following Creative Commons Licence conditions.

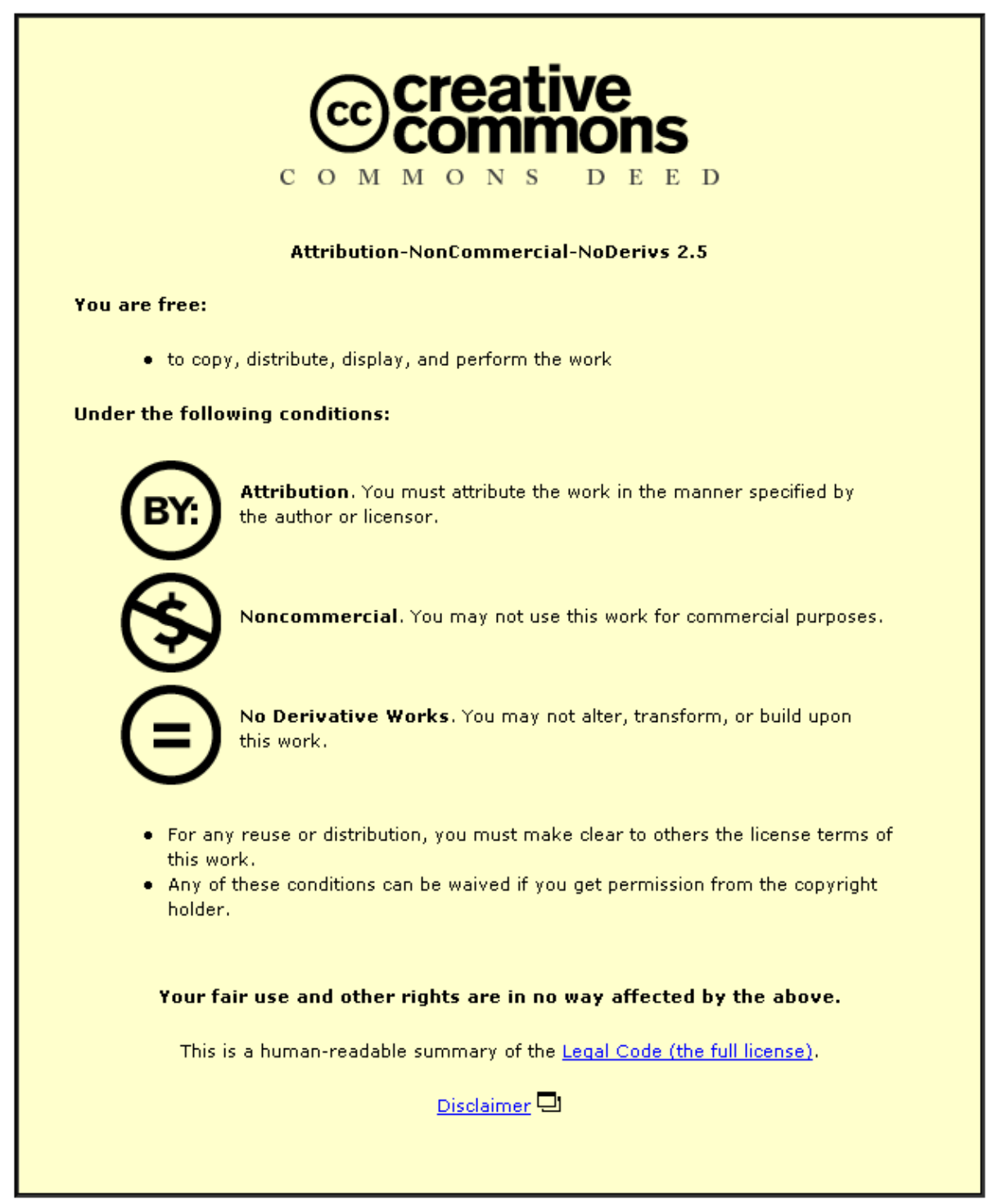

For the full text of this licence, please go to: http://creativecommons.org/licenses/by-nc-nd/2.5/ 


\title{
A multi-physics multi-scale approach in engine design analysis
}

M S M Perera, S Theodossiades*, and H Rahnejat

Wolfson School of Mechanical and Manufacturing Engineering, Loughborough University, Loughborough, Leicestershire, UK

The manuscript was received on 3 May 2006 and was accepted after revision for publication on 2 November 2006.

DOI: $10.1243 / 14644193 J M B D 78$

\begin{abstract}
Vibration behaviour of an internal combustion engine depends on rigid body inertial dynamics, structural modal characteristics of its elastic members, tribological behaviour of loadbearing contacts, and piston-cylinder interactions. Therefore, it is essential to use a multi-physics approach that addresses all these physical properties in a single integrative model as presented in this paper. This approach can be regarded as holistic and a good aid for detailed design. Particular attention is paid to the critical elements in the system, such as load-bearing conjunctions (crankshaft main bearings) and piston-cylinder wall interactions. Another important feature is the integrated analysis across the physics of motion from microscale fluid film formation to submillimetre structural deformations and onto large displacements of inertial members. In order to succeed in predictions within sensible industrial time scales, analytical methods have been used as far as possible rather than numerical approaches. Model predictions show good agreement with fired engine test data.
\end{abstract}

Keywords: tribo-elasto-multi-body dynamics, internal combustion engines, engine noise, vibration, and harshness, engine roughness, engine tribology

\section{INTRODUCTION}

Modern engine development is dominated by certain requirements. The most prominent of these is improved efficiency, which is mainly sought through reduction of losses. Within the context of solid mechanics, this requirement translates to better control of mechanical and frictional losses. The former is chiefly due to inertial imbalances in the motion of system components. Reduction in mechanical losses is, therefore, sought through decreasing mass and inertia of parts and a tighter control of out-of-balances. This trend has led to a greater use of lighter, but durable materials, which as a consequence has also led to a greater tendency in structural deformation under operating loads. Thus, a determining factor in choice

\footnotetext{
*Corresponding author: Wolfson School of Mechanical and Manufacturing Engineering, University of Loughborough, Loughborough, Leicestershire LE11 3TU, UK. email: s.theodossiades@lboro.ac.uk
}

of appropriate materials has been their structural integrity under such loads, without regard to their modal response, which as a consequence has led to a plethora of noise and vibration concerns $[\mathbf{1}, \mathbf{2}]$. It is clear that in an attempt to reduce mechanical losses due to imbalance of inertial members, sight has been lost, to a certain extent, of other potential sources of mechanical losses due to structural deformation. Ordinarily, the magnitude of effective imbalance caused by structural distortion would have been small compared to gains made by reducing inertial imbalance. However, another trend in engine development parallel to improved efficiency has been a gradual increase in output power, particularly with increasing use of diesel engines. Thus, a combination of these requirements has led to the development of more efficient and powerful, but structurally noisier engines, requiring a fair amount of noise isolation technology. A plethora of other impact-induced transmitted effects down line of engine in the drivetrain and driveline systems have also emerged [3]. The lack of a coherent and integrative analysis has been largely responsible 
for these emerging problems in an era, where much is made of concepts such as concurrent/simultaneous engineering and use of quality engineering tools.

Owing to the complexity of engine dynamics problems, simplified analytical models [4-6] and rigid multi-body models $[\mathbf{7}, \mathbf{8}]$ have been extensively used for noise, vibration, and harshness studies. Most finite element analyses have been restricted to subsystems such as the crankshaft-engine block interactions $[\mathbf{9}, \mathbf{1 0}]$ or piston skirt-cylinder liner interactions [11-13]. Such models often use simplified representation of other subsystems in order to avoid extensive computations. For example, bearings have often been modelled as linear spring-damper systems $[\mathbf{1 4}, \mathbf{1 5}]$, or distributed non-linear springs [16] or by use of the mobility method [17]. More realistic approaches include short bearing approximation with half-Sommerfeld boundary conditions as suggested by Kirk and Gunter 1975 [18]. Some other models consider gyroscopic motion of flywheel due to varying bearing reactions and component flexibility [19]. Tribological considerations for piston-cylinder interactions have largely been ignored in most engine models. This aspect of investigation has always been carried out in specific studies with very long computation times, assuming hydrodynamic or elastohydrodynamic conditions [20, 21]. It is, however, an important feature of engine dynamics and representative models of this should be incorporated in any multi-physics analysis. Even such analysis is not exactly representative of actual conditions in pistoncylinder interactions, where the regime of lubrication alters throughout the cycle and at top dead centre (TDC) and bottom dead centre (BDC) a mixed regime of lubrication is prevalent, where asperity interactions take place.

As already noted, the reactions in load-bearing conjunctions should be included in integrated engine models, which take into account frictional losses in the system, these being the other main sources of inefficiency. This has often been tackled in isolation through tribological studies of various conjunctions or combined with inertial dynamics alone, such as piston-to-cylinder contact [21], various contacts within the valve train system [22], and engine bearings. For such analyses, correctly predicted dynamic loads are critical to the behaviour of the lubricated conjunctions [23]. An ideal analysis should incorporate the load-bearing zones, which in turn affect the dynamic performance of the system as a whole. The trend for higher output power-to-weight ratio engines imposes severe conditions upon tribological conjunctions, with everdecreasing film thickness and higher shear rates, both of which can lead to an increasing rather than decreasing frictional losses.

The paper provides a multi-physics multiscale modelling approach, including tribology, small amplitude structural vibration, and large displacement inertial dynamics. The model is validated against measured data from fired engine tests.

\section{ENGINE TESTING AND MEASUREMENTS}

A single cylinder four-stroke variable compression E6 Ricardo engine having bore of 3 in, and a stroke of 4.375 in, is shown in Fig. 1. This produces a maximum power of $13 \mathrm{Bhp}$ at $3000 \mathrm{r} / \mathrm{min}$ and a maximum torque of about $40 \mathrm{Nm}$ at $1800 \mathrm{r} / \mathrm{min}$. The test was carried out at an engine speed of $1800 \mathrm{rpm}$. The test bed comprises a torque meter attached at the flywheel end, a twochannel shaft encoder with 3600 pulses per revolution, and a trigger pulse to record the position of the TDC. A Kistler plug-type pressure sensor was inserted into the combustion chamber to obtain a trace of the combustion curve. A two beam laser doppler vibrometer was also used to measure the flywheel angular velocity.

In this manner, the angular velocity of the flywheel is recorded, which provides the torsional vibration, superimposed upon the nominal angular velocity of $188 \mathrm{rad} / \mathrm{s}$. The spectral content of the signal is shown in Fig. 2. Similarly, the angular velocity of the flywheel end can be obtained from the numerical model, which contains both torsional and bending vibrations and their harmonics [24, 25].

Power torque fluctuation induces vibration in internal combustion engines in accord with the signature of the combustion process, which in a four-stroke cycle with its fundamental contribution at a half-engine order with all its higher harmonics [1]. In multicylinder engines this is usually countered by cylinder phasing, leaving only certain significant contributions according to the number of cylinders and the firing order, when a sufficiently rigid crankshaft system is employed [3]. When structural compliance is compromised to a certain extent in order to reduce the

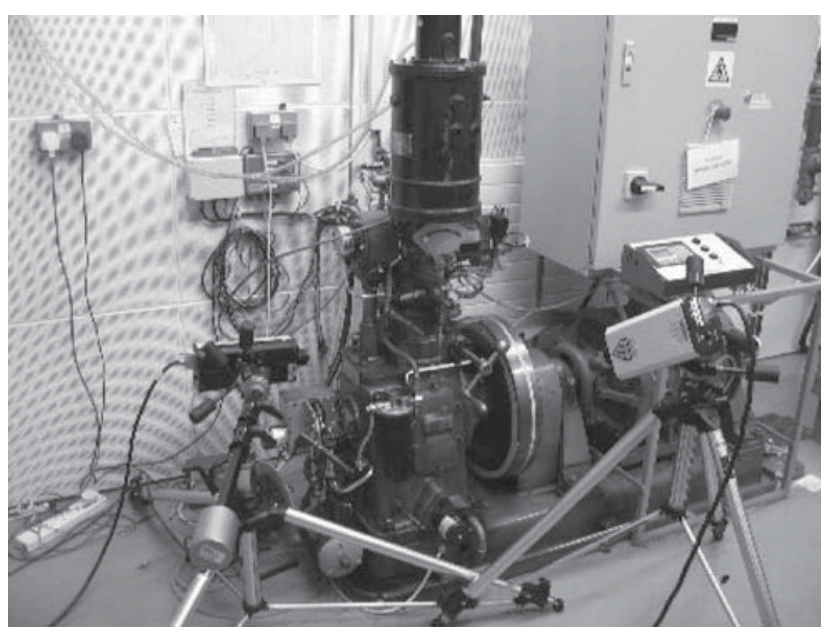

Fig. 1 Experimental set-up 


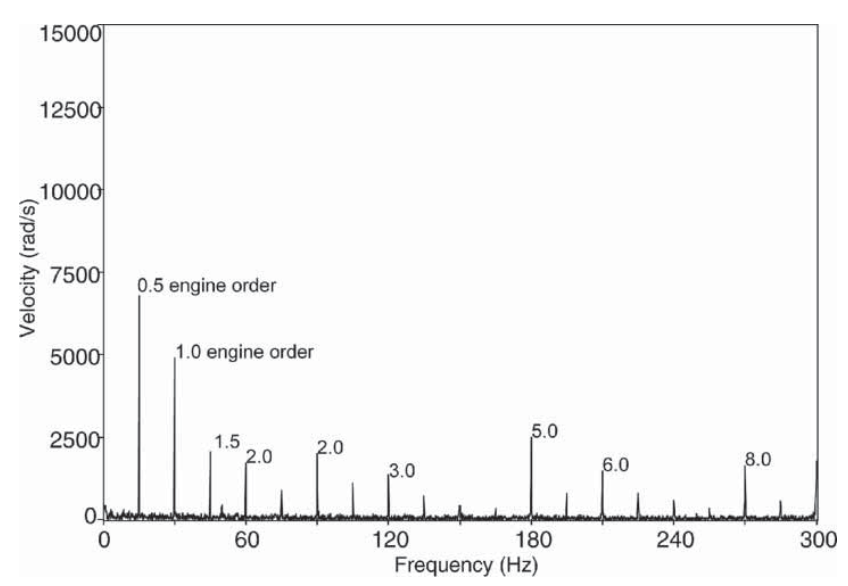

Fig. 2 Monitored spectrum of torsional vibration of the flywheel

effect of inertial imbalance, as previously discussed, the otherwise insignificant engine order contributions become significant again [3]. This is particularly true of the half-engine order responses, which are referred to as engine roughness $[\mathbf{2}, \mathbf{3}, \mathbf{2 6}]$. In the case of a four-cylinder four-stroke engine, the spectral content will be at even engine order multiples, with the fundamental at second engine order $[\mathbf{1}, \mathbf{3}, \mathbf{2 6}]$. Additional responses due to structural compliance of the crankshaft system may be regarded as undesired roughness, rather similar to parasitic output superimposed upon a clear radio frequency transmission.

The applied forces include the combustion force. The measured combustion pressure is applied onto the crown surface area of the piston. Thus, the calculated applied gas force is included in the model as a function of the crank-angle (Fig. 3). Any small variation in the gas force from cycle-to-cycle is ignored in the analysis.

With a single cylinder configuration, the opportunity to eliminate engine roughness does not exist, even

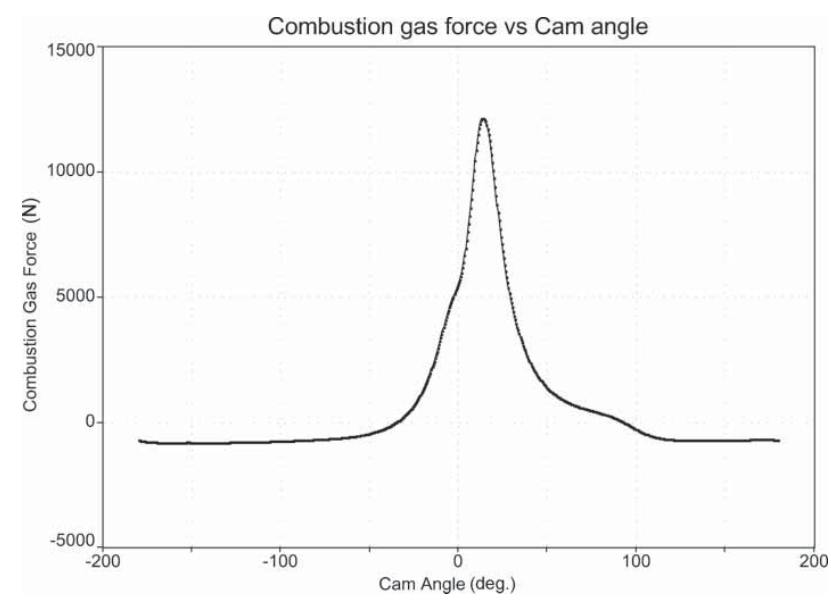

Fig. 3 A cycle of combustion gas force in the case of nominally rigid constructions, and one would expect vibratory contributions at all the aforementioned frequencies. Figure 2 corroborates this, by showing the spectral contributions at all the signature content of the four-stroke combustion process. Note that the half-engine order response is at $15 \mathrm{~Hz}$. The measured combustion force (also used as an input to the multi-physics model) is shown in Fig. 3.

\section{ENGINE MODEL}

\subsection{Multi-physics model}

As mentioned earlier, the model comprises large inertial dynamics, small elastic deformations, and tribological aspects in microscale.

\subsubsection{Inertial dynamics}

For large displacement dynamics, constrained Lagrangian formulation is employed. Thus, the core of the engine model is based on a multi-body formulation, similar to that proposed in references [7] and [27]. It consists of the main components of the system (listed in Table 1).

In a multi-body model, the parts in the system are connected to each other by holonomic and nonholonomic constraints (various joints). These are listed in Table 2 for the single cylinder engine model. The total number of degrees of freedom (DOF) of the multi-body model is obtained using the GureblerKutzbach expression as

$$
\begin{aligned}
\text { Number of DOF }= & \text { flexible body modes }(\text { flywheel } \\
& + \text { crank }+ \text { conrod })+6 \\
& \times(\text { number of rigid parts }-1) \\
& -\sum(\text { Contraints }) \\
= & (56+66+32)+6(16-1)-108 \\
= & 154+90-108 \\
= & 136
\end{aligned}
$$

Thus, the model comprises 136 DOF, including 90 rigid body motions and 154 of structural modal behaviour (Fig. 4). These are represented by a differentialalgebraic set of equations as

$$
\frac{\mathrm{d}}{\mathrm{d} t}\left(\frac{\partial L}{\partial \dot{q}_{j}}\right)-\frac{\partial L}{\partial q_{j}}+\frac{\partial D}{\partial q_{j}}-F_{q_{j}}+\sum_{k=1}^{n} \lambda_{k} \frac{\partial C_{k}}{\partial q_{j}}=0
$$

where $\left\{\xi_{j}\right\}_{j=1 \rightarrow 6}=\{x, y, z, \psi, \theta, \varphi\}^{\mathrm{T}}$ for the rigid body DOF, and $\left\{\xi_{j}\right\}_{j=6 \rightarrow 6+m}=\{x, y, z, \psi, \theta, \varphi, q\}^{\mathrm{T}}$ for the flexible bodies ( $q$ represents the modal coordinates and 
Table 1 Main components of the system

\begin{tabular}{|c|c|c|c|c|c|}
\hline \multirow[b]{2}{*}{ No. } & \multirow[b]{2}{*}{ Part description } & \multirow[b]{2}{*}{ Mass (kg) } & \multicolumn{3}{|c|}{ Moment of inertia $\left(\mathrm{kg} \mathrm{mm}^{2}\right)$} \\
\hline & & & $\mathrm{I}_{x x}$ & $\mathrm{I}_{y y}$ & $\mathrm{I}_{z z}$ \\
\hline 1 & Crankshaft (flexible) & 15.0 & 246534 & 236228 & 30071 \\
\hline 2 & Connecting rod (flexible) & 2.0 & 45305 & 849 & 45745 \\
\hline 3 & Flywheel (flexible) & 85.2 & 1329590 & 1329590 & 2454628 \\
\hline 4 & Piston & 0.5 & 1950 & 1950 & 462 \\
\hline 5 & Dummy camshaft 1 & - & - & - & - \\
\hline 6 & Dummy camshaft 2 & - & - & - & - \\
\hline 7 & Ground & - & - & - & - \\
\hline 8 & Crank dummy 1 & - & - & - & - \\
\hline 9 & Crank dummy 2 & - & - & - & - \\
\hline 10 & Crank dummy 3 & - & - & - & - \\
\hline 11 & Crank dummy 4 & - & - & - & - \\
\hline 12 & Crank dummy 5 & - & - & - & - \\
\hline 13 & Crank dummy 6 & - & - & - & - \\
\hline 14 & Crank dummy 7 & - & - & - & - \\
\hline 15 & Crank dummy 8 & - & - & - & - \\
\hline 16 & Crank dummy 9 & - & - & - & - \\
\hline 17 & Connecting rod dummy 1 & - & - & - & - \\
\hline 18 & Connecting rod dummy 2 & - & - & - & - \\
\hline 19 & Flywheel dummy & - & - & - & - \\
\hline
\end{tabular}

$m$ their total number), $L=T-V$ is the Lagrangian, which is the difference between kinetic and potential energies, and $\boldsymbol{D}=(1 / 2) \dot{\boldsymbol{q}}^{\mathrm{T}} \mathbf{Z} \dot{\boldsymbol{q}}$.

For holonomic constraints

$$
C_{n}\left(q_{j}\right)=0
$$

For non-holonomic constraints

$$
\dot{q}_{j} \frac{\partial C_{n}}{\partial q_{j}}=0
$$

Note that $F_{q_{j}}=-\partial V / \partial q_{j}$, providing the generalized forces in the Eulerian 3-1-3 body frame of reference. Those forces are listed in Table 3 . The coordinate frames discussed above are included in the system model by introducing appropriate mode shapes of the flexible members through super-element finite element modal analysis. These appropriate mode shapes within the frequency range of interest are selected using component mode synthesis [28]. Detailed explanation of the process is provided in references [29] and [30].

\begin{tabular}{|c|c|c|c|c|}
\hline No. & Part I & Part J & Constraint type & $\begin{array}{l}\text { Number of } \\
\text { constraints }\end{array}$ \\
\hline 1 & Crank dummy 1 & Connecting rod dummy 2 & Cylindrical & 4 \\
\hline 2 & Piston & Ground & Planer & 3 \\
\hline 3 & Connecting rod & Connecting rod dummy 1 & Fixed & 6 \\
\hline 4 & Connecting rod & Connecting rod dummy 2 & Fixed & 6 \\
\hline 5 & Crankshaft & Crankshaft dummy 1 & Fixed & 6 \\
\hline 6 & Crankshaft & Crankshaft dummy 2 & Fixed & 6 \\
\hline 7 & Crankshaft & Crankshaft dummy 3 & Fixed & 6 \\
\hline 8 & Crankshaft & Crankshaft dummy 4 & Fixed & 6 \\
\hline 9 & Crankshaft & Crankshaft dummy 5 & Fixed & 6 \\
\hline 10 & Crankshaft & Crankshaft dummy 6 & Fixed & 6 \\
\hline 11 & Flywheel dummy & Crankshaft dummy 6 & Fixed & 6 \\
\hline 12 & Flywheel & Flywheel dummy & Fixed & 6 \\
\hline 13 & Flywheel dummy & Crankshaft dummy 7 & Hook & 4 \\
\hline 14 & Crankshaft dummy 8 & Crankshaft dummy 9 & Hook & 4 \\
\hline 15 & Crankshaft dummy 2 & Ground & Planer & 3 \\
\hline 16 & Crankshaft dummy 4 & Ground & Planer & 3 \\
\hline 17 & Dummy camshaft 2 & Ground & Revolute & 5 \\
\hline 18 & Dummy camshaft 1 & Ground & Revolute & 5 \\
\hline 19 & Crankshaft dummy 9 & Ground & Revolute & 5 \\
\hline 20 & Connecting rod dummy 1 & Piston & Revolute & 5 \\
\hline 21 & Crankshaft dummy 7 & Crankshaft dummy 8 & Translational & 5 \\
\hline 22 & Crankshaft & Dummy camshaft 1 & Coupler & 1 \\
\hline \multirow[t]{2}{*}{23} & Crankshaft & Dummy camshaft 2 & Coupler & 1 \\
\hline & & Total & & 108 \\
\hline
\end{tabular}

Table 2 Holonomic and non-holonomic constraints (joints) 


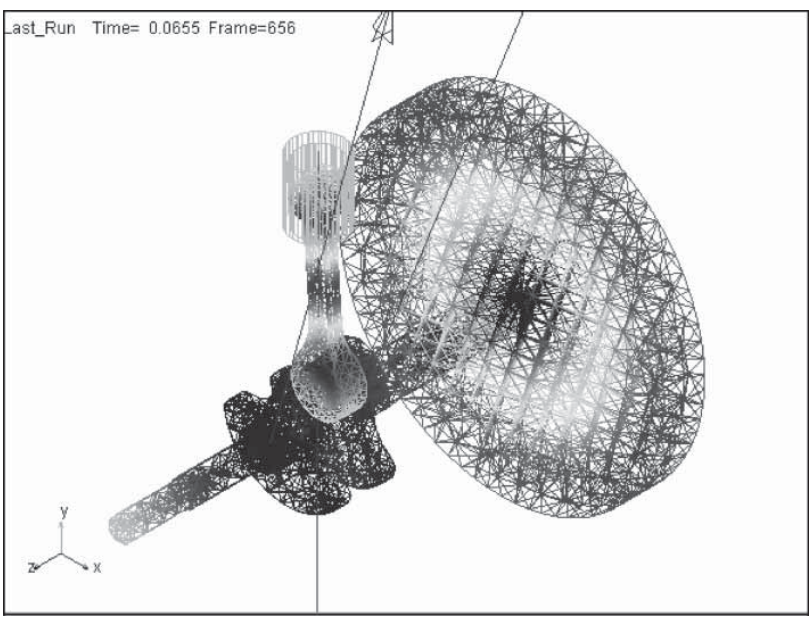

Fig. 4 The elasto-multi-body dynamic model

\subsubsection{Structural dynamics}

The forces acting on crankshaft and connecting rod are sufficiently high to make them deform under dynamic excitation. However, as the excitation is dynamic the modal excitations will create comparatively large deformations relative to the inertial frame of reference. The main excitation frequency occurs due to combustion gas force at the half-engine order, which is $15 \mathrm{~Hz}$ under the test conditions in the experimental engine. Also some significant excitations can be seen up to several hundreds Hertz.

Modal analysis for basic components was carried out and was found that the first natural frequency of the piston and pin for this engine was in the range $10000 \mathrm{~Hz}$, whereas for the crankshaft, connecting rod, and flywheel the range of few hundreds Hertz was obtained. Thus, these components have

Table 3 Internal and external forces applied

\begin{tabular}{|c|c|c|c|}
\hline No. & Type & Position & Magnitude \\
\hline 1 & $\begin{array}{l}\text { Journal bearing } \\
\text { reaction }\end{array}$ & $\begin{array}{l}\text { Left main journal } \\
\text { bearing }\end{array}$ & $\begin{array}{l}\text { Refer to } \\
\quad \text { equation (11) }\end{array}$ \\
\hline 2 & $\begin{array}{l}\text { Journal bearing } \\
\text { reaction }\end{array}$ & $\begin{array}{l}\text { Right main } \\
\text { journal bearing }\end{array}$ & $\begin{array}{l}\text { Refer to } \\
\quad \text { equation (11) }\end{array}$ \\
\hline 3 & $\begin{array}{l}\text { Combustion gas } \\
\text { force }\end{array}$ & $\begin{array}{l}\text { Perpendicular } \\
\text { to piston top } \\
\text { surface }\end{array}$ & $\begin{array}{l}\text { Figure } 3 \\
\text { represents } \\
\text { one complete } \\
\text { cycle }\end{array}$ \\
\hline 4 & Load torque & Crankshaft end & $30 \mathrm{Nm}$ \\
\hline 5 & Friction torque & Journal bearings & $\begin{array}{l}\text { Refer to } \\
\quad \text { equation (13) }\end{array}$ \\
\hline 6 & Friction at piston & $\begin{array}{l}\text { Piston top corners } \\
\text { (1 and } 2) \text { as } \\
\text { shown in Fig. } 9\end{array}$ & $\begin{array}{l}\text { Refer to } \\
\text { equation (16) }\end{array}$ \\
\hline 7 & $\begin{array}{l}\text { Normal forces at } \\
\text { piston edge }\end{array}$ & $\begin{array}{l}\text { Piston top and } \\
\text { bottom corners } \\
\text { (1 to } 4 \text { ) as } \\
\text { shown in Fig. } 9\end{array}$ & $\begin{array}{l}\text { Refer to } \\
\text { equation (15) }\end{array}$ \\
\hline
\end{tabular}

been introduced into the model as flexible bodies, as their structural modes are more likely to be excited.

The most important assumption behind this procedure is the consideration of small, linear body deformations relative to a local frame of reference, while this local frame of reference undergoes large, non-linear motions with respect to a fixed global frame of reference. The discretization of a component into a finite element model represents the infinite number of DOF with a finite, but very large number of DOF. The linear deformations of the nodes of this finite element mode, $\boldsymbol{u}$, can be approximated as a linear combination of a smaller number of shape vectors (or mode shapes), $\phi$, thus

$$
\boldsymbol{u}=\sum_{i=1}^{M} \phi_{i} q_{i}
$$

where $M$ is the number of mode shapes. The scale factors of amplitudes, $q$, are the modal coordinates.

The main concept of modal superposition is that the behaviour of a component with a very large number of nodal DOF in a predetermined frequency area can be captured with a much smaller number of modal DOF. Thus, the finite element modes can be rewritten in the matrix form as

$$
\boldsymbol{u}=\boldsymbol{\Phi q}
$$

where $\boldsymbol{q}$ is the vector of modal coordinates and the modes $\phi_{i}$ are included in the columns of the modal matrix, $\boldsymbol{\Phi}$. This matrix is the transformation from the small set of modal coordinates, $\boldsymbol{q}$, to the larger set of physical coordinates, $\boldsymbol{u}$.

The determination of the modal matrix $\boldsymbol{M}$ can be achieved due to the Craig-Brampton reduction method, which is one of the most general methods for component mode synthesis techniques [29].

According to the aforementioned, the relationship between the physical DOF and the Craig-Brampton modes and their modal coordinates is expressed as

$$
\boldsymbol{u}=\left(\begin{array}{c}
\boldsymbol{u}_{B} \\
\boldsymbol{u}_{I}
\end{array}\right)=\left(\begin{array}{cc}
\mathbf{I} & 0 \\
\boldsymbol{\Phi}_{\mathrm{IC}} & \boldsymbol{\Phi}_{\mathrm{IN}}
\end{array}\right)\left(\begin{array}{c}
q_{\mathrm{C}} \\
q_{\mathrm{N}}
\end{array}\right)
$$

where $I, 0$ are unity and zero matrices, respectively.

The generalized stiffness and mass matrices are obtained through the following transformations

$$
\begin{gathered}
\hat{\mathbf{M}}=\boldsymbol{\Phi}^{\mathrm{T}} \mathbf{M} \boldsymbol{\Phi}=\left(\begin{array}{cc}
\hat{\mathbf{M}}_{\mathrm{CC}} & 0 \\
0 & \hat{\mathbf{M}}_{\mathrm{NN}}
\end{array}\right) \\
\hat{\mathbf{K}}=\boldsymbol{\Phi}^{\mathrm{T}} \mathbf{K} \boldsymbol{\Phi}=\left(\begin{array}{cc}
\hat{\mathbf{K}}_{\mathrm{CC}} & 0 \\
0 & \hat{\mathbf{K}}_{\mathrm{NN}}
\end{array}\right)
\end{gathered}
$$

where, $\hat{\mathbf{M}}_{\mathrm{NN}}$ and $\hat{\mathbf{K}}_{\mathrm{NN}}$ are diagonal matrices and $\hat{\mathbf{K}}$ is a block diagonal matrix. 
Next, a mode shape ortho-normalization is applied, which dissolves the following problems.

1. The six rigid body modes are addressed, which can now be disabled.

2. All modes have now an associated natural frequency, which helps to classify them physically and simulate non-linear systems with unknown frequency content.

3. By solving the eigenvalue problem $\hat{\mathbf{K}} \boldsymbol{q}=\gamma \hat{\mathbf{M}} \boldsymbol{q}$, the obtained eigenvectors are arranged in a transformation matrix $\mathbf{N}$, that transforms the CraigBrampton modal basis to an equivalent, orthogonal basis with modal coordinates $\boldsymbol{q}^{*}$, where

$$
\mathbf{N} \boldsymbol{q}^{*}=\boldsymbol{q}
$$

Thus, the effect on the superposition formula is

$$
\boldsymbol{u}=\sum_{i=1}^{m} \phi_{i} \boldsymbol{q}_{i}=\sum_{i=1}^{m} \phi_{i} \mathbf{N} \boldsymbol{q}^{*}=\sum_{i=1}^{m} \phi_{i}^{*} \boldsymbol{q}^{*}
$$

where $\phi_{i}^{*}$ are the orthogonal Craig-Brampton modes.

Four-noded solid tetrahedral elements have been used with auto-mesh facility to mesh the components. Each of the connecting points of the components were replaced by a central master node, which is rigidly attached to many other nodes in the close proximity of the component. This type of connection creates a localized stiffness in the model. Since the master node DOF are independent, this node can be promoted to an attachment point and used to connect the flexible body to the neighbouring rigid bodies of the multibody model. A sufficient number of structural modes have been kept in the super-element creation to obtain the accurate results in the frequency area of interest.

\subsubsection{Tribological conjunctions}

The behaviour of tribological conjunctions like crankshaft main bearings and piston cylinder interaction during the engine operation are also considered in this multi-physics model. Many other tribological contacts are also present in an engine such as cam-tappet, timing gears, etc. Thus, the engine model described here can be regarded as the crankshaft-connecting rod-piston subsystem. In this subsystem, the main crankshaft support bearings and cylinder wall directly manipulate the behaviour of the engine crankshaft assembly during the operation. The wrist-pin (smallend) and the big-end bearings are also important in the context of engine vibration, which are represented simply here by revolute joints in this initial study.

3.1.3.1 Journal bearings. There are two journal bearings between the engine block and the crankshaft.
Lubricant is fed into the contact conjunction to prevent metal-to-metal contact.

With known geometry, kinematics, and lubricant rheology, solutions to Reynolds equation can be sought. For $2 R / \ell \geqslant 2$, engine bearings can be approximated to short-width bearings. An analytic solution can be obtained, where the pressure distribution is given as [31]

$$
p=\frac{3 U \eta_{0} \varepsilon}{R_{\mathrm{j}} c}\left(\frac{\ell^{2}}{4}-\Upsilon^{2}\right) \frac{\sin \alpha}{(1+\varepsilon \cos \alpha)^{3}}
$$

To determine the pressure distribution the following parameters are required.

1. The speed of entraining motion of the lubricant in the contact, $\boldsymbol{u}$. This is given as $U=1 / 2 \omega R_{\mathrm{j}}$.

2. The eccentricity ratio, $\varepsilon=e / c$, where $e$ is the "line of sight' excursion of the centre of the journal away from the fixed position of the bearing bushing (Fig. 5, and note that the film thickness, $h=$ $c(1+\varepsilon \cos \tau))$. Note that $c$ is the designed nominal radial clearance, typically $1 / 250 \geqslant c / R_{\mathrm{j}} \geqslant 1 / 2000$.

Therefore, the unknowns required for the tribological analysis $e$ and $\omega$ are obtained from the dynamic analysis, where $e=R_{\mathrm{i}}-R_{\mathrm{j}}$.

A number of assumptions have been made, in addition to the short bearing assumption $\left(2 R_{\mathrm{j}} / \ell>2\right)$. First, the bearing bushing is considered to have a sufficient thickness, and made of a material of high elastic modulus in order to discount its deformation due to generated lubricant pressures. In the case of the E6 engine, under investigation here, such an assumption can be made. However, most modern engines employ thin shells, made of material of low elastic modulus (such as tin-based alloys) in order to encourage localized deformation, and retention of a lubricant film by elasto-hydrodynamic regime of lubrication [2].

Second, under hydrodynamic conditions and with lubricant film assumed to be formed over a circumferential extent of $\pi$ radians, the area of contact, $\pi \ell$, is large and thus the generated pressures are insufficient to appreciably alter the bulk lubricant viscosity from

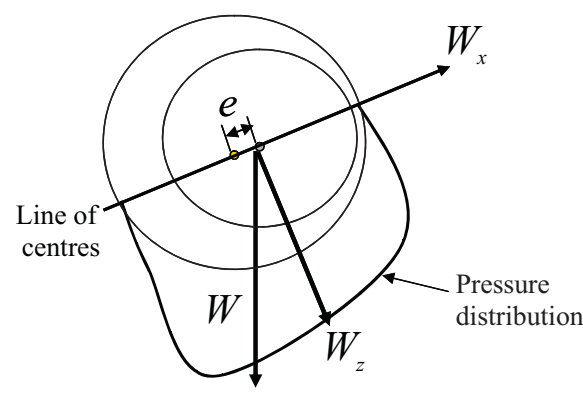

Fig. 5 Pressure distribution and bearing reactions 
its value under atmospheric condition, $\eta_{0}$ (iso-viscous assumption).

Finally, the solution provided here is isothermal, not taking into account the fall in the lubricant viscosity.

With the pressure distribution determined, using equation (10), lubricant reactions (restoring forces) are usually given as load components $W_{x}$ and $W_{z}$ along and perpendicular to the line of centres (Fig. 5), respectively. Using the half-Sommerfeld's boundary conditions (pressure is generated in the region $0 \leqslant \tau \leqslant$ $\pi)$, then

$$
\left\{\begin{array}{l}
W_{x}=\frac{U \eta_{0} \ell^{3}}{4 c^{2}} \frac{\pi \varepsilon}{\left(1-\varepsilon^{2}\right)^{3 / 2}} \\
W_{z}=\frac{U \eta_{0} \ell^{3}}{c^{2}} \frac{\varepsilon^{2}}{\left(1-\varepsilon^{2}\right)^{2}}
\end{array}\right.
$$

The resultant reaction is obtained as (Fig. 5) $W=\sqrt{W_{x}^{2}+W_{z}^{2}}$

The friction force in a lubricated conjunction is given by relative sliding motion of the two contacting surfaces. Here $U_{\mathrm{j}}$ refers to the surface velocity of the journal, where as $U_{\mathrm{b}}$ denotes the surface velocity of the bush bearing [31]

$$
F=\int_{0}^{\ell}\left(\frac{h}{2} \frac{\partial p}{\partial x}+\frac{\eta_{0}\left(U_{\mathrm{b}}-U_{\mathrm{j}}\right)}{h}\right) \mathrm{d} x
$$

Note that $U_{\mathrm{b}}=0$, and that the first term in the integral disappears with short bearing assumption as $\partial P / \partial x=$ 0 . Thus, noting that $x=R_{\mathrm{j}} \tau, h=c(1+\varepsilon \cos \tau), \dot{\psi}=\omega$

$$
F=-\int_{0}^{\pi} \frac{U_{\mathrm{j}} \eta_{0} \ell R_{\mathrm{j}}}{c(1+\varepsilon \cos \alpha)} \mathrm{d} \alpha=-\frac{\pi \eta_{0} \dot{\psi} R_{\mathrm{j}}^{2} \ell}{c} \frac{1}{\sqrt{1-\varepsilon^{2}}}
$$

The negative sign indicates opposition to the direction of motion. Thus, friction torque for any of the support bearings is given as $T_{\mathrm{f}}=F R_{\mathrm{j}}$.

3.1.3.2 Piston interaction with cylinder wall. Piston skirt-cylinder wall interaction is sought by solving the Reynolds equation for an iso-viscous lubrication system with known kinematics and lubricant rheology. Also the long bearing assumption is used as circumferential length of the contact is much larger than that of its width. Reynolds equation is solved using the long bearing approximation $(2 R / \ell<0.5)$, with no side leakage as the circumference $\ell$ of the skirt is very much greater than that of its thickness. The film thickness in between the piston skirt and the wall is assumed as a parabola along the direction of the flow as shown in Fig. 6. Note that the skirt profile is assumed to be

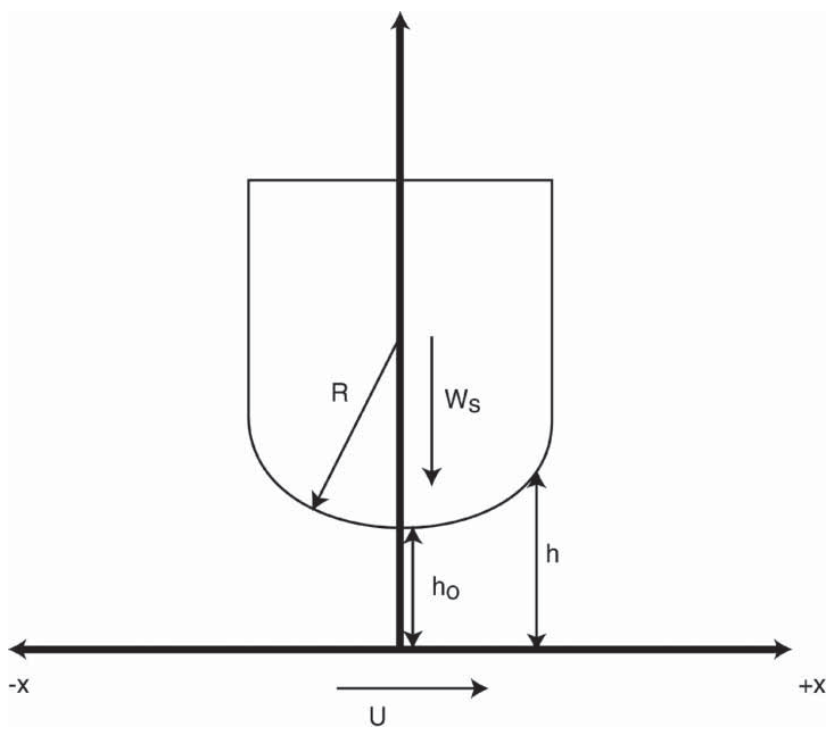

Fig. 6 Piston ring-cylinder wall contact conjunction

parabolic and is given as follows [32]

$$
h=h_{0}\left(1+\frac{x^{2}}{2 R h_{0}}\right)
$$

In reality, the piston skirt profile in the axial direction is a barrel shape for the engine under consideration, with a very large radius. This has been approximated to a parabola.

The dimensionless pressure distribution can be obtained as follows [33]

$$
\begin{aligned}
P^{*}= & \frac{1}{8} \bar{x}-\frac{1}{32} \sin 4 \bar{x}-\tan ^{2} \bar{x}_{a} \\
& \times\left(\frac{3}{8} \bar{x}+\frac{1}{4} \sin 2 \bar{x}+\frac{1}{32} \sin 4 \bar{x}\right) \\
& +\frac{4 W_{\mathrm{s}}^{*}}{\sqrt{2 h_{0}^{*}}}\left[-\frac{3}{32}-\frac{1}{8} \cos 2 \bar{x}-\frac{1}{32} \cos 4 \bar{x}\right. \\
& \left.+\tan \bar{x}_{a}\left(\frac{3}{8} \bar{x}+\frac{1}{4} \sin 2 \bar{x}+\frac{1}{32} \sin 4 \bar{x}\right)\right] \\
& +\frac{\pi}{16}\left(1-3 \tan ^{2} \bar{x}_{a}+\frac{12 W_{\mathrm{s}}^{*}}{\sqrt{2 h_{0}^{*}}} \tan \bar{x}_{a}\right)
\end{aligned}
$$

Dimensionless parameters in this equation are given in the appendix.

When deriving this equation it is assumed that the inlet and outlet are fully flooded as explained in reference [34]. The calculated pressure variation right through the contact conjunction for some dimensionless approaching velocities are given in Fig. 7.

When the approaching velocity is zero $\left(W_{s}^{*}=0\right)$, the pressure distribution is that of the half Sommerfeld condition. However, negative pressures are discarded when calculating the load, as fluid cannot support loads with negative pressures and also it gives zero 


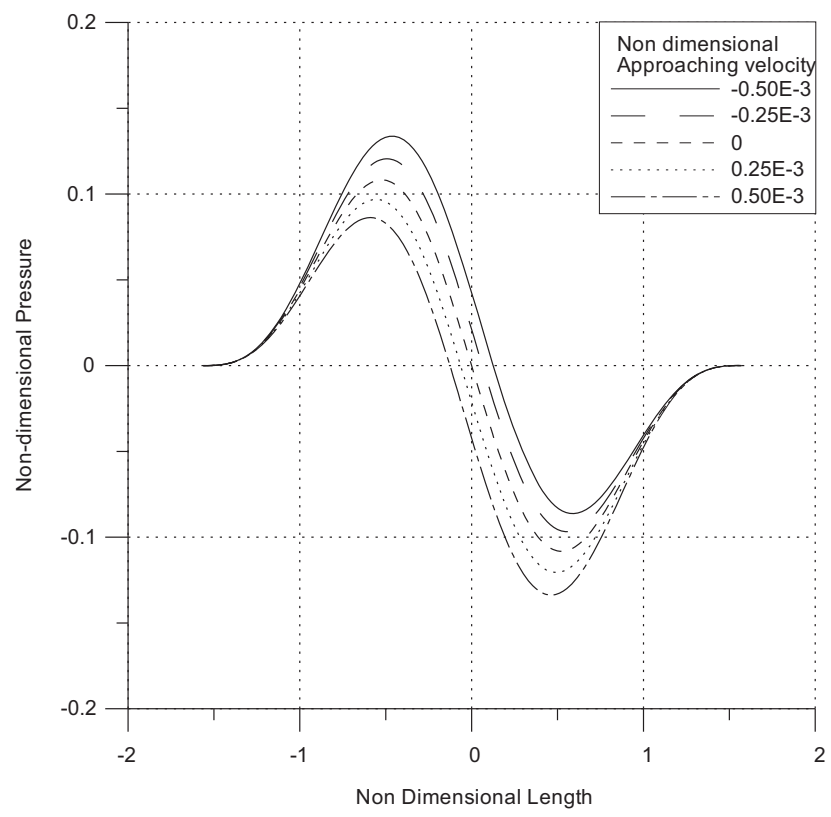

Fig. 7 Pressure variation in ring-wall contact conjunction

cumulative load carrying capacity, which is not correct as shown in reference [31]. Then, the resultant load is calculated taking into consideration only the positive pressures and it is applied on the piston as a reaction force acting on the piston skirt.

Surface traction force (or the friction force) acting on the piston along the piston skirt opposing the piston translational motion is calculated, considering the viscous drag acting on the contact conjunction. Viscous drag force is given by Gohar [31] as

$$
\tau= \pm \underbrace{\frac{h}{2} \frac{\mathrm{d} P}{\mathrm{~d} x}}_{a}+\underbrace{\eta_{0} \frac{\Delta U}{h}}_{b}
$$

In hydrodynamic lubrication, the contribution from the pressure gradient on the viscous drag is very small as shown Gohar [31], so the component due to pressure gradient is neglected.

The initial clearance $h_{0}$ can be obtained as follows (for the contact point 1 in Fig. 9)

$$
h_{0}=x_{L}-a \sin \vartheta-r_{\mathrm{tt}} \cos \vartheta
$$

For simplicity, it is considered that only four corners of the piston touch the cylinder wall when the piston is in operation (due to its secondary motions, lateral and tilting) and these four positions are shown numbered in Figs 8 and 9 (points 1 to 4). This approach follows that of Haddad and Howard [35], who used the four corner model with spring-damper elements, which are clearly not representative of tribological conditions.

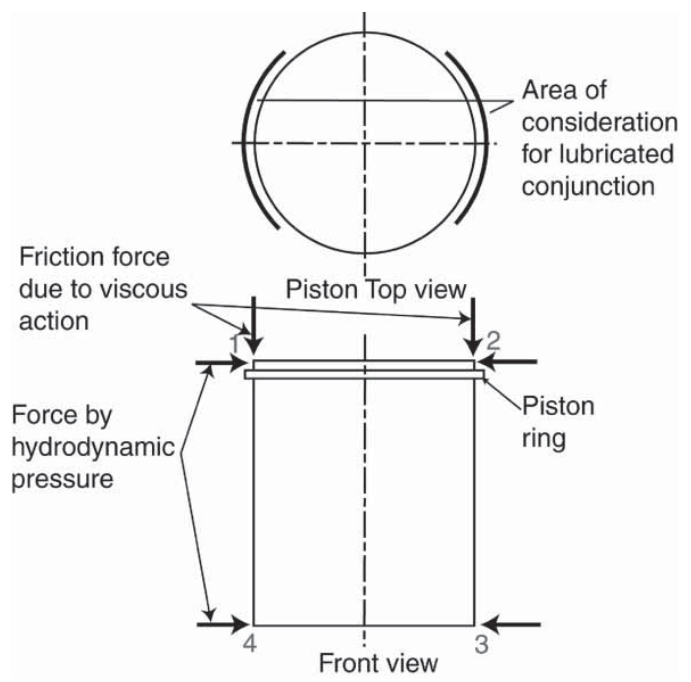

Fig. 8 Forces acting on piston skirt

Force component due to pressure variation is orthogonal to the piston surface at these four corners of the piston as shown in Fig. 8.

It should be noted that at the extremities of the cycle (at TDC and BDC) due to cessation of lubricant entraining motion (reversal in sliding velocity), any lubricant film is retained by squeeze film action or trapped in between asperities of the contiguous surfaces. It is generally accepted that a mixed regime of lubrication occurs in such locations, where asperity interactions occur. The friction force in such instances is a combination of viscous action, described

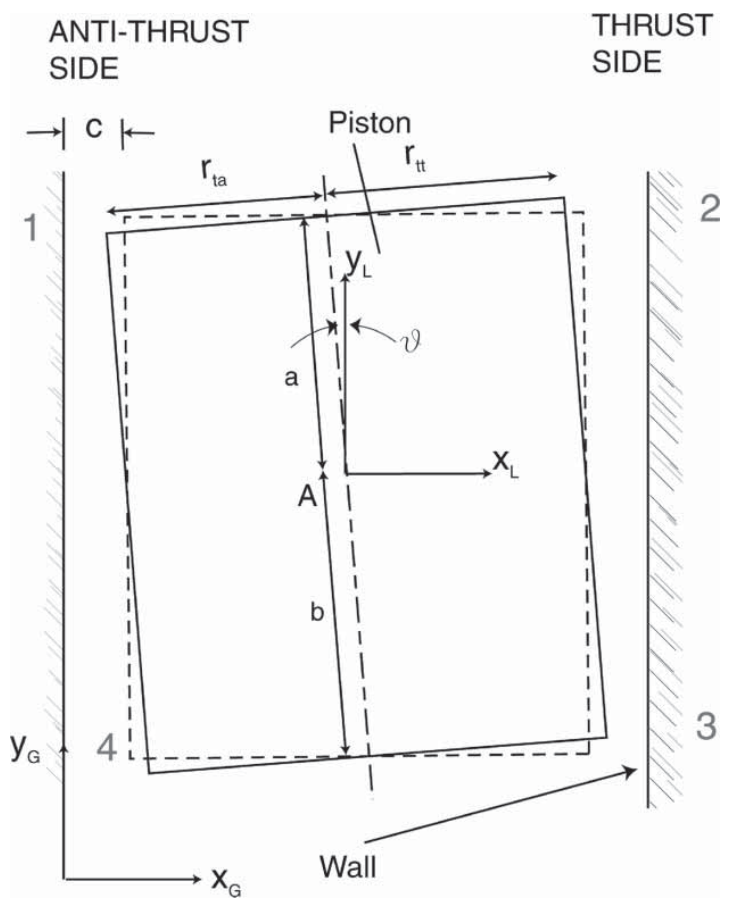

Fig. 9 Piston tilting 
above, and that due to asperities (known as boundary contribution). Solutions for boundary friction have been provided by Greenwood and Tripp [36], based on non-Newtonian behaviour of very thin films at asperity tips. For the engine investigated here, the nominal clearance is quite large $(100 \mu \mathrm{m})$, and side force $(\max .300 \mathrm{~N})$ and piston tilt $\left(\leqslant 0.1^{\circ}\right)$ are relatively low. Thus, hydrodynamic regime of lubrication as the first approximation is reasonable for piston skirt to cylinder liner contact. Future extension of this model should take into account boundary interactions at TDC and BDC, particularly with much thinner films encountered between the piston ring and the cylinder liner.

\section{RESULTS AND DISCUSSION}

Figure 10 shows the spectrum of torsional vibration of the flywheel predicted using the multi-physics numerical model outlined above. The frequency composition agrees with the experimentally obtained spectrum (Fig. 2). The amplitudes also compare well, except for the contribution at the fundamental combustion frequency at the half-engine order. It is not possible to have a rigorous agreement on amplitude, due to a number of reasons. First, with the real engine, other factors such as dry friction and viscous action in the big-end bearing also contribute to friction torque, which are not included in the model. Second, FFT is essentially an averaging process, and one cannot rely on the obtained amplitudes in either case. Nevertheless, good agreement is obtained, validating the proposed analysis method.

Figure 11 shows the variation of the predicted viscous friction force and the lubricant film thickness on the thrust side. Note that a film thickness of around

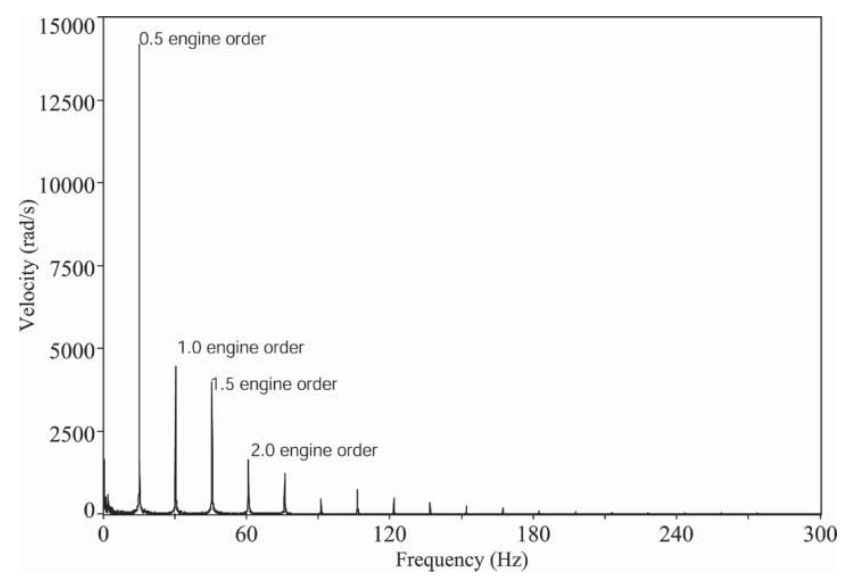

Fig. 10 Analytically predicted spectrum of torsional vibration of the flywheel

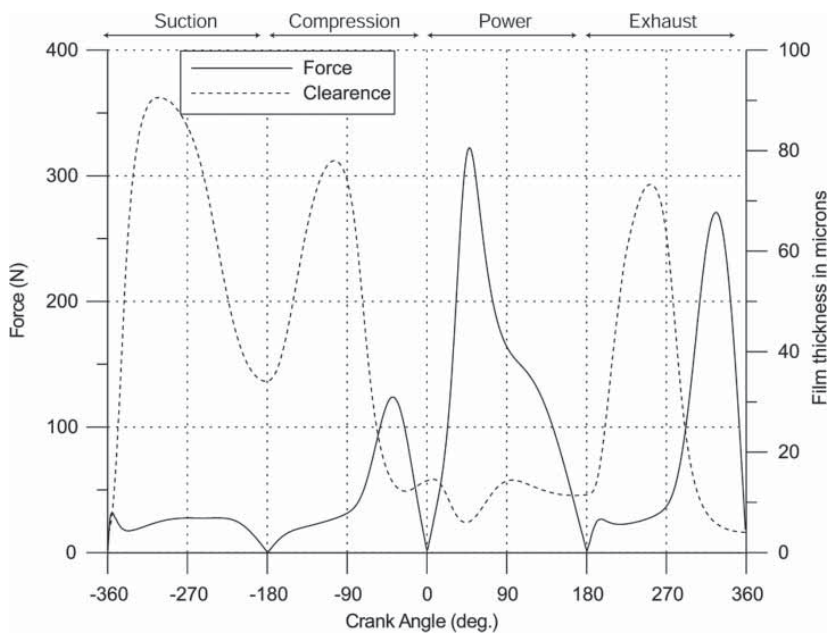

Fig. 11 Viscous force and the clearance (film thickness) variation at thrust side

$15 \mu \mathrm{m}$ is predicted at the TDC, all due to rigid secondary motion towards the thrust side (with the nominal clearance being $100 \mu \mathrm{m}$ ). In more modern engines, the clearance is tighter and film thickness retained is usually much lower, resulting in mixed regime of lubrication. Piston stops instantaneously at the TDC and the $\mathrm{BDC}$ during reversal. At these positions no viscous friction force can be expected, as there is momentarily no relative motion of contiguous surfaces. Due to the cessation of entraining motion (i.e. $\boldsymbol{u}=0$ ), any lubricant film is retained in these locations by entrapment due to squeeze film effect (i.e. the viscous action of the lubricant flowing out of the contact is slower than the approach of piston towards the cylinder wall). Thus, the film thickness attains its minima in these locations, as shown in the figure $\left( \pm 360^{\circ}\right.$ and $0^{\circ}$ crank angles, belonging to the TDC, and $\pm 180^{\circ}$ crank angle, belonging to the BDC). Note that the nominal designed clearance for this engine is $100 \mu \mathrm{m}$.

Close to the TDC, the film thickness is small compared to that at the BDC. This is because hydrodynamic conditions are dominant, and the greater side force at the TDC, acting on the piston tends to keep the piston closer to the wall. The side force is in fact quite low (with a maximum value of around $300 \mathrm{~N}$ during the power stroke, as expected). This is not the case for most modern engines that exhibit much larger contact forces. If the side force was sufficient to cause local deformation of contiguous solids, the regime of lubrication would tend to elastohydrodynamics, and a larger film thickness would probably be expected at TDC than BDC. However, for the E6 engine, this is not the case, but in modern engines with, for example, aluminium pistons, elastohydrodynamic conditions are more likely to occur.

At the mid span of piston motion, the sliding velocity is higher. This tends to pull more lubricant into 
the contact by entraining action. Thus, a larger film thickness is observed in each of the cycles at mid span, except at the power stroke. During the power stroke, the piston is pushed towards the thrust side by the tangential force component $\left(F_{\mathrm{s}}\right.$ in Fig. 14$)$ in the connecting rod. This results in a smaller film thickness.

As the film thickness is very small during the power stroke, the viscous friction force is much higher. During other strokes the film thickness is comparatively larger and the friction force is correspondingly lower. The maximum combustion gas force is applied soon after the TDC. At this point, the side force (thrust force) attains its maximum value. Furthermore, near to the TDC the sliding velocity is low, leading to a smaller film thickness soon after the TDC as shown in the figure.

Almost the opposite case arises for film thickness in the antithrust side as shown in Fig. 12. At the end of the exhaust stroke, the film thickness is at its maximum and the friction force reaches its minimum value. The rapid oscillatory variations in force shown in this figure and those in Fig. 13 have no physical significance. These occur in the vicinity of reversal positions and are due to mathematical inaccuracy due to integration time step size, which should ideally be reduced. However, such a reduction leads to significant rise in computation times.

It is interesting to examine force variation in the piston during its motion. In Fig. 14 the forces due to combustion gas force, $F_{p}$ and the inertia force, $F_{i}$, acting on the piston during its downward motion during the suction stroke are shown. These two forces have to be balanced by the force, $F_{R}$, acting on the connecting rod. Even though vertical component, $F_{d}$ on the connecting rod is balanced by $F_{p}$ and $F_{i}$, the horizontal component, $F_{s}$ has to be balanced by the thrust reaction from the cylinder wall. Viscous friction force acting at the piston-wall interface is given as $F_{F}$.

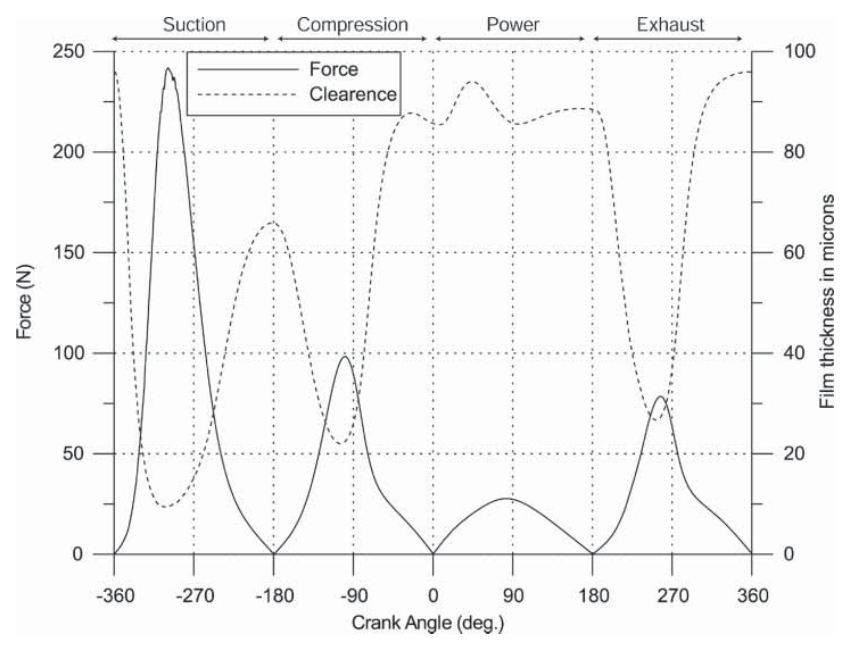

Fig. 12 Viscous force and clearance (film thickness) variation in antithrust side

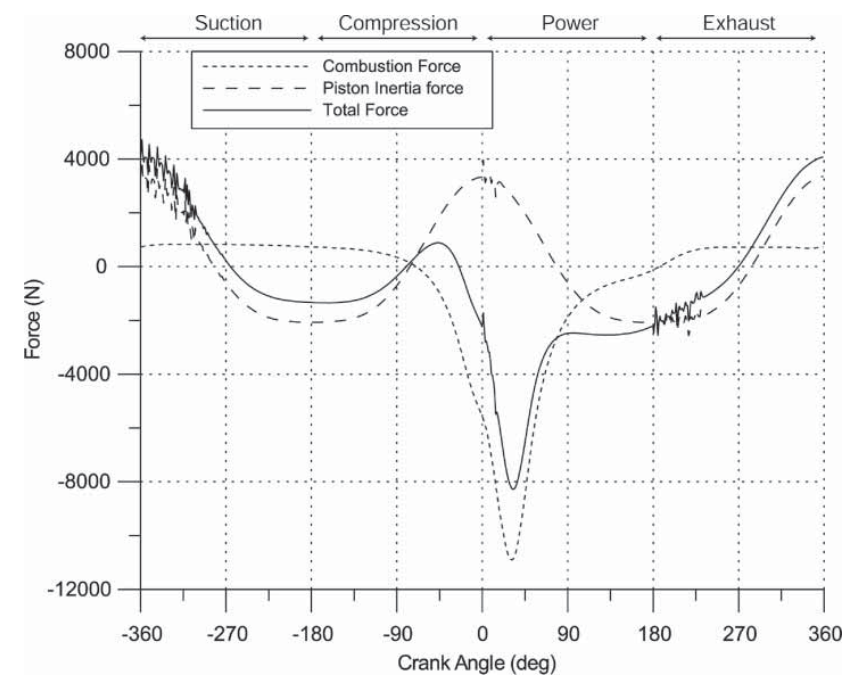

Fig. 13 Predicted forces acting on the piston

The horizontal force variation in the piston is shown in Fig. 13. The inertial component on the piston is very high, thus there is a corresponding high vertical force component at the onset of the suction stroke and at the end of the exhaust stroke. This leads to a higher side force during suction stroke on the antithrust side as shown in Fig. 12 and a higher side force during exhaust on the thrust side as shown in Fig. 11. During the combustion stroke, the vertical force $F_{p}+F_{i}$ is negative and the piston is pushed against the connecting rod. This load reversal leads to a force on the thrust side during the power stroke.

Piston axial (primary motion) acceleration and velocity are shown in Fig. 15. Some fluctuations of

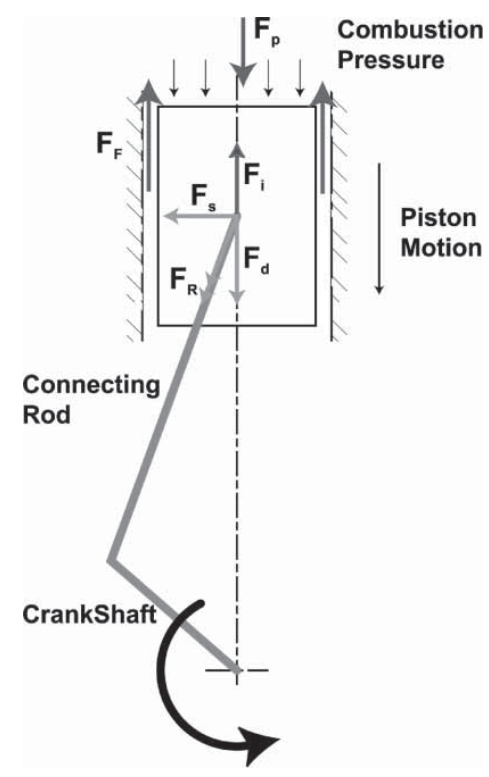

Fig. 14 Forces acting on the piston during successive strokes 


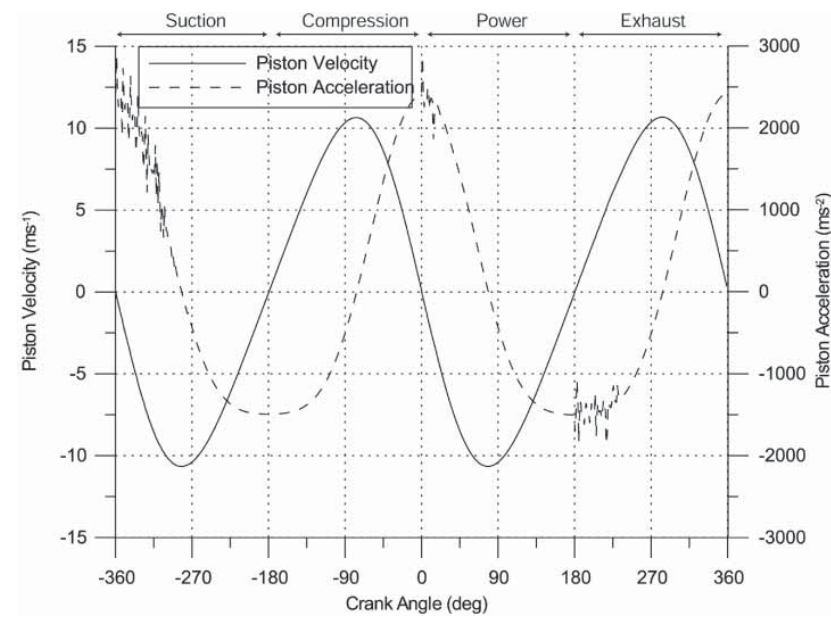

Fig. 15 Piston acceleration and velocity variations

the piston acceleration can be seen at the dead centres. The maximum acceleration can be seen at the TDC. At the TDC, external forces (force due to combustion) acting on piston are high (Table 3). This can be seen in Fig. 3. At $\pm 360^{\circ}$ and $0^{\circ}$ crank positions the gas force is high compared to $\pm 180^{\circ}$ crank position, which represents the TDC.

Figure 16 shows the piston tilting motion during a combustion cycle. During the power stroke the piston is oriented towards the thrust side. During the suction cycle it adheres to the antithrust side. The resulting friction force variation can be seen in Fig. 17. During the compression stroke, the total friction force is low compared to other strokes. Higher values can be seen in the other parts of the cycle with slight variations. Both vertical force and friction force reach maximum values during the power stroke as expected, when the dominant regime of lubrication is hydrodynamic.

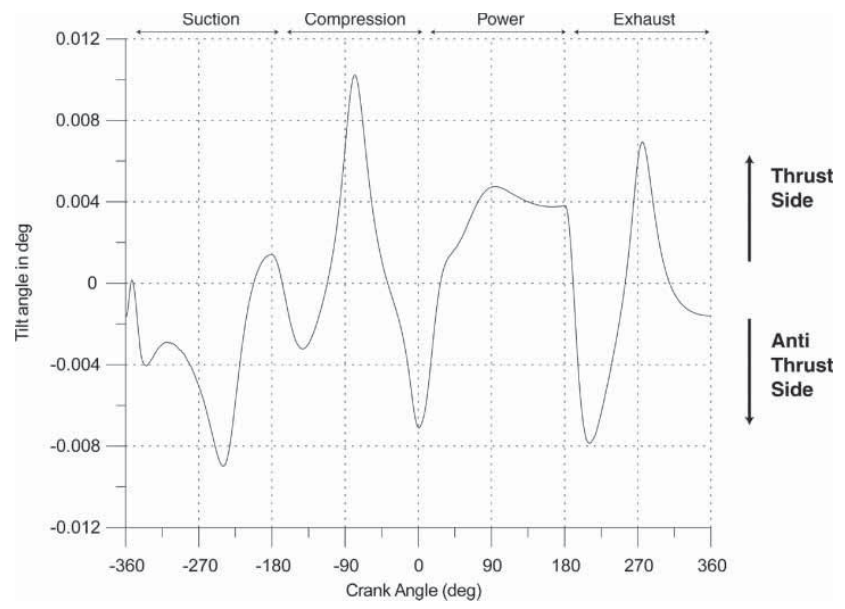

Fig. 16 Piston tilting motion during its cycle

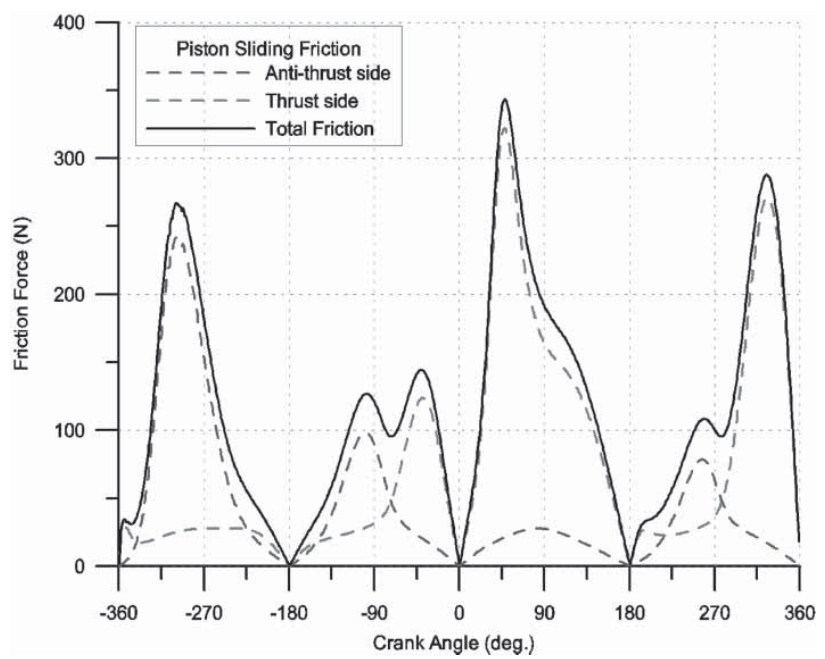

Fig. 17 Friction force on the piston

As described in section 1, minimization of losses is a key design objective in modern engine development. The frictional losses in an engine are mostly attributed to piston-cylinder wall interactions, and cam-tappet contact (this is not modelled here). However, engine bearings also account for 10 to 15 per cent of frictional losses, while generation of friction torque is also vital in the control of torsional vibration of the crankshaft system. Figure 18 shows the coefficient of friction variation in an engine bearing during a cycle. In real engines low values, in the range 0.0050.08 would indicate full fluid film lubrication. This is obviously the case here, as is predicted by the model. However, a ten-fold variation in the coefficient of friction belies the complexity of engine running conditions and serves the purpose for its demonstration. To illustrate the reasons behind these variations,

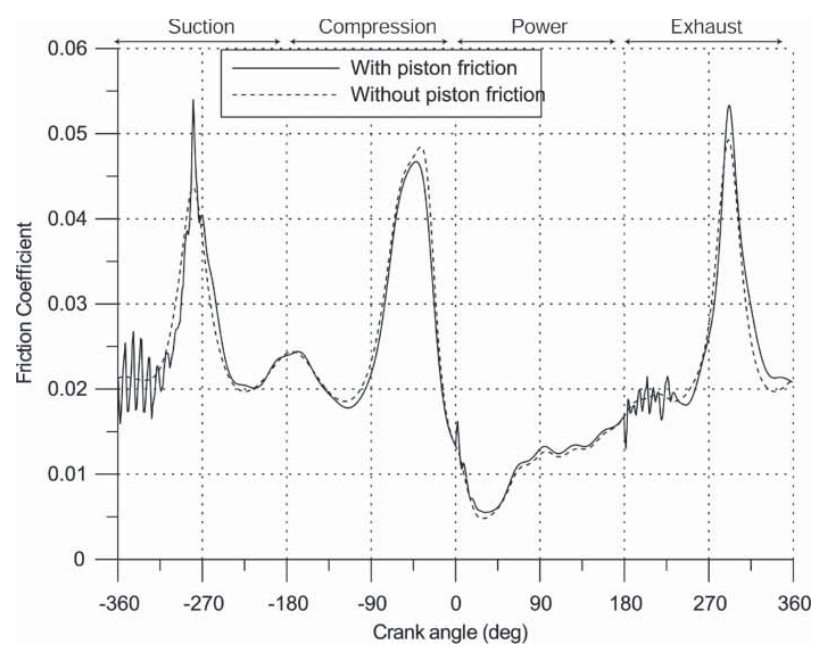

Fig. 18 Variation of coefficient of friction in an engine bearing during the four-stroke cycle 


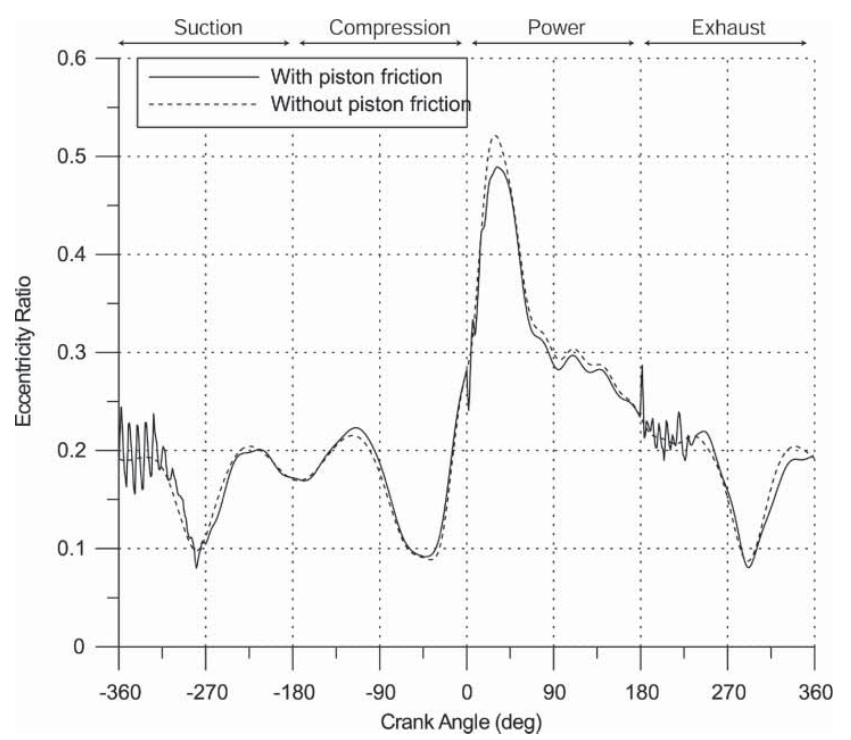

Fig. 19 Variation of bearing eccentricity ratio during the four-stroke cycle

Fig. 19 shows the transient nature of the eccentricity ratio, with Fig. 20 illustrating the resultant bearing reaction. As $\varepsilon$ increases due to combustion force, the bearing generates a higher reaction due to greater hydrodynamic pressures, which in turn tend to separate the surfaces. The friction force, on the other hand, decreases with an increase in the value of $\varepsilon$. Therefore, coefficient of friction is predicted to have its lowest value at the maximum combustion force (crank-angle position of $11^{\circ}$ ) and its highest values, indicated by the three peaks in Fig. 18 (first and the last corresponding to successive cycles in reaching the BDC, and the middle peak corresponding to approaching

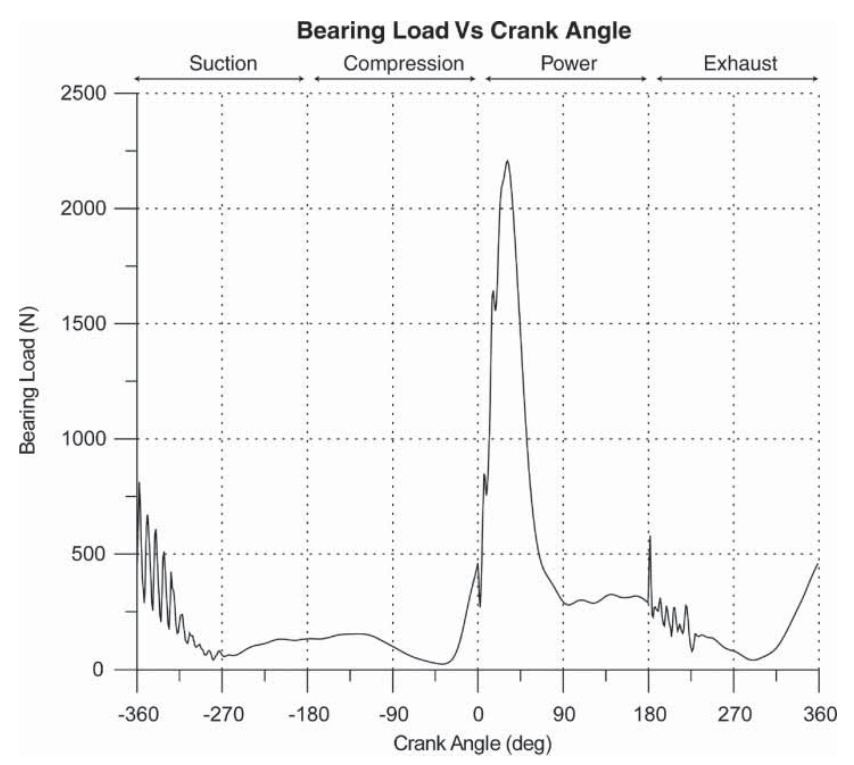

Fig. 20 Bearing load variation with the crank angle the position of the TDC). Note that the applied gas force dramatically drops in these cases (Fig. 3). Finally, a word of caution is that the model does not include thermal effects and shear thinning of the lubricant, which can result in the diminution of film thickness and non-Newtonian friction in the piston-cylinder wall interactions at TDC and BDC. Further work is required to include these practical features within the multi-physics model, but its multi-disciplinary nature already shows better promise as a design tool than the traditional multi-body dynamic analysis techniques.

\section{CONCLUSIONS AND FUTURE WORK}

The paper presents a multi-physics approach to engine analysis, incorporating inertial and flexible multi-body dynamics, as well as contact mechanics and tribological considerations. Clearly, it is important to include certain level of detail to represent prevailing conditions. This would often lead to very complex and computational intensive models, with the repercussion of impracticality for design analysis time scales in industry. The paper shows that some simplified assumptions can be made to render timely analysis, while retaining sufficient useful detail. Validation of the model against measurements shows the validity of the overall approach. However, this approach has the drawback of omission of certain salient details, such as the proper representation of tribological contact conditions at, for example, reversal points in piston to cylinder contact, where a mixed regime of lubrication is prevalent. The approach, however, opens the way for inclusion of such detail in future developments.

\section{REFERENCES}

1 Rahnejat, H. Multi-body dynamics: vehicle, machines, and mechanisms, 1998 (Professional Engineering Publishing, London and SAE (Co-Publishers), Warrendale, Pennsylvania, USA).

2 Rahnejat, H. Multi-body dynamics: historical evolution and application. Proc. Instn Mech. Engrs, Part D: J. Automobile Engineering, 2000, 214(D1), 149.

3 Kushwaha, M., Gupta, S., Kelly, P., and Rahnejat, H. Elasto-multi body dynamics of a multi-cylinder internal combustion engine. Proc. Instn Mech. Engrs, Part K: J. Multi-body Dynamics, 2002, 216, 281-293.

4 Cho, M.-R., Kim, J.-S., Oh, D.-Y., and Han, D.-C. The effects of crankshaft offset on the engine friction. Int. J. Veh. Des., 2003, 31(2), 187-201.

5 Cho, S.-H., Ahn, S.-T., and Kim, Y.-H. A simple model to estimate the impact force induced by piston slap. J. Sound Vibr., 2002, 255(2), 229-242.

6 Nakayama, K., Tamaki, S., Hiroyuki, M., and Takiguchi, M. The effect of crankshaft offset on piston friction force in a gasoline engine. Soc. Autom. Eng., 2000, paper no. 2000-01-0922. 
7 Boysal, A. and Rahnejat, H. Torsional vibration analysis of a multi-body single cylinder internal combustion engine model. Appl. Math. Model., 1997, 21(8), 481-493.

8 Ma, Z.-D. and Perkins, N. C. An efficient multibody dynamics model for internal combustion engine systems. Multibody Syst. Dyn., 2003, 10(4), 363-391.

9 Du, H. Y. I. Simulation of flexible rotating crankshaft with flexible engine block and hydrodynamic bearings for a V6 engine. SAE techincal paper series, 1999.

10 Ebrat, O., Mourelatos, Z. P., Hu, K., Vlahopoulos, N., and Vaidyanathan, K. An elastohydrodynamic coupling of a rotating crankshaft and a flexible engine block. J. Tribol., 2004, 126(2), 233-241.

11 Gerges, S. N. Y., De Luca, J. C., and Lalor, N. The influence of cylinder lubrication on piston slap. J. Sound Vibr., 2002, 257(3), 527-557.

12 Kurbet, S. N. and Kumar, R. K. A finite element study of piston tilt effects on piston ring dynamics in internal combustion engines. Proc. Instn Mech. Engrs, Part K: J. Multi-body Dynamics, 2004, 218(K2), 107-117.

13 Offner, G., Krasser, J., Laback, O., and Priebsch, H. H. Simulation of multi-body dynamics and elastohydrodynamic excitation in engines especially considering piston-liner contact. Proc. Instn Mech. Engrs, Part K: J. Multi-body Dynamics, 2001, 215(K2), 93.

14 Morita, T. and Okamura, H. Dynamic stiffness matrix approach to the analysis of three-dimensional vibrations of automobile engine crankshafts. Part 2. Application to firing conditions. Winter Annual Meeting of the American Society of Mechanical Engineers, Dallas, TX, USA, 25-30 November 1990, pp. 59-66.

15 Okamura, H., Shinno, A., Yamanaka, T., Suzuki, A., and Sogabe, K. Simple modeling and analysis for crankshaft three-dimensional vibrations, part 1: background and application to free vibrations. J. Vibr. Acoust., Trans. ASME, 1995, 117(1), 70-79.

16 Mourelatos, Z. P. Efficient crankshaft dynamic analysis using substructuring with Ritz vectors. J. Sound Vibr., 2000, 238(3), 495-527.

17 Katano, H., Iwamoto, A., and Saitoh, T. Dynamic behaviour analysis of internal combustion engine crankshafts under operating conditions. International Conference on Computers in Engine Technology, 1012 September 1991; Proc. Instn Mech. Engrs, Part C: J. Mechanical Engineering Science, 1991, 205, 205-216.

18 Kirk, R. G. and Gunter, E. J. Short bearing analysis applied to rotor dynamics. J. Lubr. Technol., Trans. ASME, 1975, 98F(1), 47-56.

19 Okamura, H. and Morita, T. Efficient modelling and analysis for crankshaft three-dimensional vibrations under firing conditions. Proc. Instn Mech. Engrs, Part K: J. Multi-body Dynamics, 1999, 213(K1), 33-44.

20 Knoll, G. D. and Peeken, H. J. Hydrodynamic lubrication of piston skirts. Trans. ASME, J. Lubr. Technol., 1982, 104, 504-509.

21 Balakrishnan, $\mathbf{S}$. and Rahnejat, $\mathbf{H}$. Isothermal transient analysis of piston skirt-to-cylinder wall contacts under combined axial, lateral and tilting motion. J. Phys. D, Appl. Phys., 2005, 38(5), 787-799.

22 Teodorescu, M., Kushwaha, M., Rahnejat, H., and Taraza, D. Tribo-elasto multi body dynamics of valve train systems under transient conditions. Proc.
IMechE, Part K: J. Multi-body Dynamics, 2005, 219, 13-25.

23 Dowson, D., Ruddy, B. L., and Economou, P. N. Elastohydrodynamic lubrication of piston rings. Proc. R. Soc. Lond., Ser. A: Math. Phys. Sci., 1983, 386(1791), 409-430.

24 Hoffman, D. M. W. and Dowling, D. R. Fully coupled rigid internal combustion engine dynamics and vibrationpart I: model development. J. Eng. Gas Turbines Power, 2001, 123(3), 677-684.

25 Hoffman, D. M. W. and Dowling, D. R. Fully coupled rigid internal combustion engine dynamics and vibration - part II: model-experiment comparisons. J. Eng. Gas Turbines Power, 2001, 123(3), 685-692.

26 Dixon, J., Rhodes, D. M., and Phillips, A. V. The generation of engine half orders by structural deformation. IMechE Conference on Vehicle NVH and Refinement, London, UK, 1994, vol. 3, p. 9.

27 Zeischka, J., Mayor, L. S., Schersen, M., and Maessen, F. Multi-body dynamics with deformable bodies applied to the flexible rotating crankshaft and the engine block. ASME 94 Fall Technical Conference, Lafayette, USA, 1994.

28 Craig, R. R. and Brampton, M. C. C. Coupling of substructures for dynamics analysis. AIAA J., 1968, 6, 1313-1319.

29 Theodossiades, S., Gnanakumarr, M., Rahnejat, H., and Menday, M. Mode identification in impact-induced high-frequency vehicular driveline vibrations using an elasto-multi-body dynamics approach. Proc. Instn Mech. Engrs, Part K: J. Multi-body Dynamics, 2004, 218(K2), 81-94.

30 Gnanakumarr, M., Theodossiades, S., Rahnejat, H., and Menday, M. Impact-induced vibration in a vehicular driveline systems: theoretical and experimental investigations. Proc. IMechE, Part K: J. Multi-body Dynamics, 2005, 219, 1-12.

31 Gohar, R. Elastohydrodynamics, 1988 (Ellis Horwood Ltd, Chichester).

32 Cameron, A. The principles of lubrication, 1966 (Longmans, London, UK).

33 Rahnejat, H. Influence of vibration on the oil film in concentrated contacts, 1984 (University of London, London).

34 D'Agostino, V., Valle, S. D., Ruggiero, A., and Senatore, A. A study on the piston top ring lubrication using the open-end boundry condition. Aimeta International Tribology Conference, Italy, 2002.

35 Haddad, S. D. and Howard, D. A. Analysis of piston slap-induced noise and assessment of some methods of control in diesel engines. SAE preprints, 800517-25, 1980.

36 Greenwood, J. A. and Tripp J. H. The contact of two nominally flat surfaces. Proc. Instn Mech. Engrs, 1971, 185, 625-633.

\section{APPENDIX 1}

\section{Notation}

a distance of piston top to pin (m)

$b$ distance of piston bottom to pin (m)

c clearance (m)

$C_{k} \quad$ constraint function 
D

e

F

$F_{q}$

FFT

$h$

$h_{0}$

K

$\ell$

$L$

$p$

$P$

$q_{j}$

$q_{\mathrm{C}}$

$q_{\mathrm{N}}$

$r$

$r_{\mathrm{ta}}$

$r_{\mathrm{tt}}$

$R$

$R_{\mathrm{j}}$

$R_{\mathrm{i}}$

$t$

$T$

$T_{\mathrm{f}}$

$u$

$\boldsymbol{u}_{\mathrm{B}}$

$\boldsymbol{u}_{\mathrm{i}}$

$U$

$U_{\mathrm{b}}$

$U_{\mathrm{j}}$

V damping energy dissipation function

bearing eccentricity (m)

force $(\mathrm{N})$

generalized applied forces $(\mathrm{N})$

fast Fourier transformation

film thickness (m)

minimum hydrodynamic film thick-

ness (m)

kinetic energy ( $\mathrm{J}$ )

bearing length $(\mathrm{m})$

Lagrangian ( $\mathrm{J}$ )

pressure inside the lubricated conjunction $(\mathrm{Pa})$

combustion force $(\mathrm{N})$

generalized coordinates

generalized constrained coordinates

generalized normal coordinates

crank radius (m)

piston radius on the antithrust side $(\mathrm{m})$

piston radius on the thrust side (m)

effective radius of the contact (m)

radius of the journal $(\mathrm{m})$

radius of the bearing bushing $(\mathrm{m})$

time (s)

kinetic energy ( $\mathrm{J})$

friction torque (Nm)

nodal deformation vector

boundary nodal deformation vector

interior nodal deformation vector

relative velocity or speed of entraining

motion $(\mathrm{m} / \mathrm{s})$

surface velocity of the bearing bush-

$\operatorname{ing}(\mathrm{m} / \mathrm{s})$

surface velocity of the journal $(\mathrm{m} / \mathrm{s})$

potential energy $(\mathrm{J})$

$\begin{array}{ll}W_{\mathrm{s}} & \partial h / \partial t, \text { squeeze velocity }(\mathrm{m} / \mathrm{s}) \\ x, y, z & \text { cartesian coordinates } \\ \alpha & \text { circumferential position (rad) } \\ \gamma & \text { eigen value } \\ \Delta U & \text { sliding velocity }(\mathrm{m} / \mathrm{s}) \\ \varepsilon & \text { eccentricity ratio } \\ \eta_{0} & \text { atmospheric dynamic viscosity (Pa.s) } \\ \vartheta & \text { piston tilt angle (degree) } \\ \lambda_{k} & \text { Lagrange multiplier } \\ \mu & \text { coefficient of Friction } \\ \Upsilon & \text { distance along the length of the bear- } \\ & \text { ing (m) } \\ \phi & \text { mode shape } \\ \phi_{\text {IC }} & \text { interior constraint modes } \\ \phi_{\text {IN }} & \text { interior normal modes } \\ \psi, \theta, \varphi & \text { euler angles (rad) } \\ \omega & \text { crank angular velocity (rad/s) }\end{array}$

\section{APPENDIX 2}

Non-dimensional quantities used in equation (15)

$$
\begin{aligned}
\tan \bar{x}= & \frac{x}{\sqrt{2 R h_{0}}} \\
\tan \bar{x}_{a}= & \frac{x_{a}}{\sqrt{2 R h_{0}}}, \text { position of maximum } \\
& \text { hydrodynamic pressure } \\
P^{*}= & \frac{h_{0}^{3 / 2} P}{6 U \eta_{0}(2 R)^{1 / 2}} \\
W_{\mathrm{s}}^{*}= & \frac{W_{\mathrm{s}}}{U} \\
h_{0}^{*}= & \frac{h_{0}}{R}
\end{aligned}
$$

